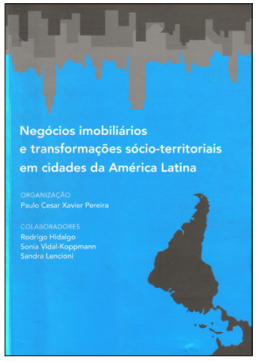

\title{
Paulo Cesar Xavier Pereira (org.), Rodrigo Hidalgo, Sonia Vidal- Koppmann, Sandra Lencioni (col.). Negócios imobiliários e transformações sócio-territoriais em cidades da América Latina
}

\author{
São Paulo: FAUUSP, 2011. 368 p.
}

Alex Paulsen E. ${ }^{1}$

Maurice Halbawachs, señalaba que "El capital corría como el aire en una aspiradora", cuando se refería a la situación vivida en París durante el Segundo Imperio, a partir de la modificaciones realizadas por Haussmann, a mediados del siglo XIX (1). Este mismo capital que caracterizaba las relaciones entre un nuevo sistema financiero y el desarrollo de la ciudad en el París decimonónico, es parte de la realidad urbana actual de las ciudades de América Latina. Esta analogía pretende evidenciar la principal idea del libro que pasamos a reseñar, a saber, que "Nas transformações sócio-territoriais das grandes ciudades, em especial, essa dinámica imobiliaria rentista e sua associação com o setor financiero vem acentuando a desigualdade e a segregação, que a par das mudanças na centralidade urbana alteram profundamente o uso e a ocupação do territorio" (Pereira, y otros, 2011: 9). Para comprender esta realidad, se hace necesario articular a los agentes, los productos y la segregación que están generando los negocios inmobiliarios y su estrecha relación con los capitales financieros. Estos conceptos son un marco analítico para comprender las ciudades y la nueva forma de producción social del espacio, según Pereira.

Llevado a cabo por autores de diversos países y diferentes disciplinas, este texto nos muestra las dinámicas propias de los agentes

\footnotetext{
1 Magíster (C) en Geografía y Geomática. Instituto de Geografía, Pontificia Universidad Católica de Chile (Chile). E-mail: appaulse@uc.cl
}

involucrados en el desarrollo de la ciudad, así como también, las transformaciones inmobiliarias y sus consecuencias a nivel territorial. De esta guisa, en la primera parte, llamada Agentes e transformações imobiliárias, se presentan ocho estudios que constatan los cambios sufridos por ciudades como São Paulo, Santiago de Chile y Buenos Aires, entre otras. El primero de ellos, escrito por el organizador del libro, Paulo Cesar Xavier Pereira, denominado Agentes imobiliários e reestruturação: intereses e conflitos na construção da cidade contemporânea, nos propone una reflexión en torno a las características de la reestructuración socioespacial como proceso propio de las ciudades de América Latina durante el siglo XX. La producción de nueva ciudad, se remonta a la crisis del modelo económico imperante en las ciudades del hemisferio Sur, específicamente del modelo de sustitución de importaciones, el cual estableció dos patrones diferentes de urbanización, siendo por un lado una "urbanización sin urbanismo", caracterizada por construcciones propias de los trabajadores, ubicadas en la periferia de las aglomeraciones y otra en donde se dieron edificaciones avanzadas en el centro de las ciudades. Sin embargo, con la crisis de este modelo, se comienzan a establecer alianzas urbanoindustriales que establecen estrategias que promueven el crecimiento de las ciudades a manos del sector financiero. Esto se hace patente con el caso de estudio presentado por Carlos Teixeira de Campos Júnior, titulado Transformações imobiliárias e incorporação de Vitoria (ES) ao circuito do mercado imobiliário nacional. En dicho artículo se exponen 
ocurridos en Vitoria a partir de la evolución de la actividad inmobiliaria y las consecuencias que esta genera, como por ejemplo, la fragmentación y también el hecho de que las prácticas inmobiliarias actúan en el límite de la legislación, con el fin de maximizar las utilidades.

Por su parte, Lucia Zanin Shimbo, en Cidades médias carimbadas: a produção imobiliária por empresas construtoras de capital aberto, analiza el crecimiento y desarrollo de una empresa constructora, que bajo una apertura incesante de los capitales financieros, presenta un incremento de sus inversiones y construcciones, realizadas para un sector específico de la sociedad: la clase media. Lo interesante de todas las relaciones que establece la autora, es principalmente el nexo que se aprecia entre esta empresa y el financiamiento proveniente desde el Estado, lo cual favorece las operaciones financieras de dicha empresa. "Esses números confirman a maior participação dos bancos, tanto a CAIXA como os demais, no financiamento para o cliente adquirir a unidade residencial e, concomitantemente, uma diminuição do financiamento direto com a ECP- significando menores riscos nas suas operações financeiras" (Pereira, y otros, 2011: 56). El siguiente trabajo, realizado por Helena Menna Barreto Silva, nos muestra el panorama ocurrido en el área central de São Paulo a fines del siglo XX, y que tiene que ver con una de las situaciones más notorias de las ciudades de América Latina: el centro histórico y su rehabilitación. En Transformações no quadro imobiliário do centro de São Paulo no inicio dos anos 2000, Barreto nos pone al día sobre las actuaciones del capital en el centro de São Paulo, y sobre todo en lo referido a la dinámica inmobiliaria, poblacional y las iniciativas públicas y privadas en lo referido a la rehabilitación. De esta manera se hace un análisis de la evolución inmobiliaria del centro histórico, tomando en cuenta la situación de la habitación social y también la vivienda dirigida a sectores de renta media en el área de estudio, en donde las acciones y propuestas que tenían como fin mejorar el centro, estuvieron marcadas por contradicciones. "Na questão habitacional, fica evidente o conflito entre instrumentos para atração de classe média e a luta por habitação social no centro" (Pereira, y otros, 2011: 81). Se concluye que existe un conflicto entre la producción de habitación de interés social y las propuestas de recuperación del centro implementadas por la prefectura desde 2005.

La transformación de las áreas centrales en América Latina: agentes inmobiliarios y nueva morfología urbana en el caso de Santiago de Chile, Rodrigo Hidalgo establece un panorama sobre los cambios experimentados en el Área Metropolitana de Santiago, a partir de las consecuencias generadas por los negocios inmobiliarios a nivel comercial, residencial y demográfico, entre otros. Por lo tanto se caracterizan los planes de renovación y repoblamiento aplicadas en Santiago, así como también las zonas de mayor crecimiento comercial. El autor establece que esta nueva geografía social no estaría relacionada con los procesos de gentrificación, y que la gestión pública "debe tener en todo caso un criterio histórico, cultural, geográfico y por sobre todo valorar la dimensión social" (Pereira, y otros, 2011: 111) al momento de llevar a cabo la renovación del espacio central. Mientras tanto, la situación de Buenos Aires en lo referido a las urbanizaciones cerradas, es un tema abordado por Sonia Vidal Koppmann, quien articula en sus análisis a dos actores que producen la ciudad: públicos y privados. La autora se concentra en el periurbano de la ciudad de Buenos Aires, en donde los actores privados han creado una geografía espacial marcadamente contrastada por diferencias sociales. La conformación de urbanizaciones cerradas (Vidal establece que estas no son necesariamente privadas, ya que algunas poseen un perímetro cercado al igual que las de sectores acomodados), tanto de viviendas sociales como de conjuntos habitaciones para las clases medias altas, se han establecido de forma desintegrada de la ciudad, evidenciando "que desde el ámbito privado como desde el estatal, no han sido suficientes los esfuerzos para que el crecimiento del parque habitacional quedara integrado al tejido urbano preexistente" (Pereira, y otros, 2011: 116), así como tampoco entre dichas urbanizaciones. Mientras tanto, actores públicos y privados se han visto envueltos en conflictos que han quedado expuestos a la luz pública, debido a que en detrimento de los sectores sociales de clases bajas, los agentes privados han realizado modificaciones a terrenos aledaños a dichos sectores, provocando 
anegamientos y otros problemas. Bajo esta misma línea, referida a la ciudad privada, Viviana Riwilis, analiza el caso de Nordelta en Buenos Aires bajo la lógica de la "Génesis de una ciudad privada: Estado local, promotores inmobiliarios y residentes. El caso de Nordelta en Buenos Aires". Esta investigación aborda la génesis del megaproyecto residencial Nordelta, en función de los actores estatales, privados y los residentes. En virtud de esto, se tratan de establecer los roles que han jugado cada uno de estos actores en la formación de esta ciudad privada. Bajo esta perspectiva, existe una imbricación entre lo público y lo privado, ya que la aprobación del proyecto, acordada por diferentes instancias gubernamentales, es señalada como una inversión privada que aumenta los recursos de la municipalidad. Esto implica, según el discurso del Estado local, un desarrollo económico que se redistribuye a toda la población" (Pereira, y otros, 2011: 152). Las consecuencias de esto ha generado que el Estado local se haya subyugado a los intereses inmobiliarios, y a fin de cuentas sean los actores privados los principales beneficiados económicamente. Estas consecuencias sociales y espaciales que se generan en este contexto, también son parte de la Ciudad de México, las cuales son tratadas por Patricia Eugenia Oliveira en La ciudad y la gestión neoliberal en el caso de México. En este caso, se constatan las consecuencias generadas por el establecimiento de las políticas neoliberales y su relación con las desigualdades. Estas políticas neoliberales han marcado la evolución de una ciudad industrial a una ciudad global fragmentada, ya que la Ciudad de México es "una ciudad cada vez más terciarizada, con servicios al productor, comercio y actividades informales; no obstante, sigue siendo el principal centro industrial del país" (Pereira, y otros, 2011: 167). Ahora bien, sus efectos a nivel territorial, también son consecuencias de la gestión urbana que se adopte por parte del gobierno local, el cual ha adoptado "directrices de mercado, privatización, competitividad, desregulación desde $\mathrm{FMI}, \mathrm{BM}, \mathrm{OMC}, \mathrm{OECD}{ }^{\prime \prime}$ (Pereira, y otros, 2011: 175). Nuevamente, nos encontramos frente a una característica común dentro de las ciudades de América, esto es, espacios "desconectados del resto de la ciudad (...) y la reproducción de un sistema social cada vez más desigual" (Pereira, y otros, 2011: 179).
La segunda parte, versa sobre las consecuencias y transformaciones que han generado estas actuaciones del capital sobre las ciudades latinoamericanas, es decir, la segregación. En este sentido, el primer artículo que se presenta en este apartado, es sobre los "Condomínios industriais: um novo nicho dos negócios imobiliarios". Estos nuevos condominios industriales se analizan en virtud de ser lugares de producción del capital, ya que los negocios inmobiliarios están "interéssando o sector imobiliario industrial" (Pereira, y otros, 2011: 190), estableciéndose como un sector emergente en los negocios inmobiliarios. Asimismo, pone en duda las características colectivas de un condominios, por lo que asevera que si bien su adjetivo está referido a lo colectivo, este no tiene un sentido de acceso universal. Esto se aplicaría a una ciudad caracterizada por los condominios, lo cual señalaría la mercantilización del espacio a nivel regional. Bajo esta premisa es que la siguiente investigación se relaciona con esta idea de la mercantilización de la ciudad, ya que las consecuencias se estarían territorializando a partir de la formación de una ciudad injusta. De esta forma, Raúl Fernández trae a colación la investigación denominada "La ciudad injusta. La política pública y las tranformaciones residenciales en el Área Metropolitana de Buenos Aires". Se analizan en dicho texto las actuaciones que ha tenido la política pública en Buenos Aires y su responsabilidad en la conformación de esta ciudad injusta, a partir de medidas que restringen el acceso al suelo por parte de los sectores populares. Estas medidas están dadas por la política habitacional y urbana que se ha llevado a cabo por parte de los actores públicos, generándose un debate en torno al acceso a la ciudad, por lo que la apropiación del espacio público y el acceso a los servicios esenciales, alcanzan ya tales niveles que vuelven evidente la necesidad de otra intervención del Estado en el suelo" (Pereira y otros, 2011: 228). En esta misma línea de investigación, Beatriz Goldwaser, Lidia Soria, Cecilia Chiasco, Adriana Pereyra y Rosana Repetto, en "Los procesos de expansión y segregación residencial en la Región Metropolitana de Buenos Aires (RMBA), Argentina. Aportes teórico-metodológicos", tratan los efectos de la globalización en la RMBA, a través de la fragmentacion territorial que esta ha producido. En tal sentido, este proceso global 
ha generado diferentes tipos de urbanización como las urbanizaciones cerradas. Empero, los aportes teóricos y metodológicos de esta investigación, entregan nuevas herramientas para el análisis socioterritorial de los efectos de la globalización. Se establecen conceptos tales como metrópolis dual y "el abordaje de la trialéctica socioterritorial (...) es decir, la segregación residencial, el impacto socioeconómico-ambiental y la ordenación del territorio" (Pereira y otros, 2011: 233). Mientras que desde la perspectiva metodológica se observan estrategias como la "secue-observación", "intranexo" y las encuestas sistematizadas.

La producción del territorio bajo la localización industrial es analizada por Eliseu Savério Sposito, teniendo como área de estudio los espacios metropolitanos, ya que estos son un centro de innovación, y las ciudades medias, debido a que estas últimas desempeñan un papel complementario a las ciudades metropolitanas. Se destaca la idea de develar, por parte del autor, esta lógica espacial capitalista por medio de las estrategias empresariales y los patrones de localización de estas, no perdiendo de vista el rol que juega el Estado en esta dinámica.

En el siguiente capítulo, "Caracas fragmentada y segregada: una construcción desde la normativa y política urbana", Sandra Ornés Vásquez analiza las características de la normativa urbanística y sus implicancias a nivel socioterritorial, verificando un patrón constante en las ciudades de América Latina: la segregación. Este se ve reflejado en la "configuración de ghettos exclusivos para los sectores de altos ingresos, de ámbitos deteriorados o relegados a la periferia para los sectores medios y de verdaderos apartheid sociales para los grupos populares" (Pereira y otros, 2011: 274). Estas mismas situaciones serán verificadas por Julia Virginia Rofé, quien desarrolla el tema "Segregación socioespacial y la exclusión en Buenos Aires en el siglo XXI", enfatizando la acción de los actores privados como productores de un espacio de exclusión, pero haciendo hincapié en el hecho de que ha sido el Estado un intermediario, a través de su política habitacional, el que ha facilitado aún más esta configuración espacial desigual. Abordando esta misma problemática en el partido de San Isidro, pero desde la óptica de los imaginarios sociales, Elisa Gra- ciela Carlevarino nos introduce en las consecuencias que genera la segregación a nivel territorial, pero tomando en cuenta la visión de los vencedores y los vencidos, es decir, rescatando las percepciones e imaginarios de quienes están en los órganos estatales y quienes sufren finalmente la implementación de las políticas desde el Estado. Se aprecia la existencia de metodologías cuantitativas y cualitativas como estrategia para abordar los imaginarios sociales.

En "Desarrollos habitacionales en la periferia de la Ciudad de México. Consideraciones de accesibilidad para una estructura polinuclear", Paula Negrón Poblete Ileva a cabo un interesante análisis sobre los efectos de la red de transporte en el desarrollo social de la población que reside en habitaciones de interés social. Es menester señalar que las constataciones de la investigadora revelaron que "la tarifa única del metro y de los autobuses de la Red de Transporte Público del Distrito Federal jugaban un papel importante en la consolidación de los barrios pobres de la periferia metropolitana mediante la disminución de los gastos de transporte asociados con la movilidad cotidiana de los habitantes de estos barrios" (Pereira y otros, 2011: 329). Asimismo, se constata que la movilidad es un aspecto importante para lograr una vida social más óptima y una inserción de los grupos localizados en las periferias de las ciudades. Mientras, Eduardo Alberto Cusce Nobre, en "As transformações socioespaciais recentes da Região Metropolitana de São PauIO", contextualiza las situación actual de esta ciudad a partir de los efectos generados por el paradigma fordista de urbanización. El autor evidencia que a partir de la decada de los 90 , esta región metropolitana sufre cambios en los usos de suelo pasando de un uso residencial a uno comercial, así como también la pérdida de población en las áreas centrales, la cual se constituirá en la periferia para el caso de los sectores populares y la formación de condominios cerrados dentro de esta misma periferia, pero poblados por sectores medios y altos.

Los análisis e investigaciónes plasmadas en este texto, dan cuenta de variadas realidades dentro del contexto latinoamericano. Sin embargo, existen efectos y consecuencias similares para esta realidad 
de globalización y de circulación de un capital financiero que se territorializa bajo externalidades negativas en América Latina: segregación urbana, pérdida de "Estado", gentrificación, tugurización, desigualdad y polarización social. Por su parte, este urbanismo neoliberal que se ha establecido en las ciudades de este continente, ha conllevado a la formación de una ciudad revanchista, en donde las políticas urbanas no tan solo han facilitado las tareas a este capital financiero, sino que han pasado a ser un mediador e intermediario entre esta nueva morfología urbana y la financiarización de la ciudad. En concomitancia con lo anteriormente dicho, es que los aportes teóricos y metodológicos realizados en los artículos de este libro, son fundamentales para (de) construir la dinámica inmobiliaria, la cual se caracteriza por no tener regularidades y comportamientos permanentes.

Asismismo, se valora la construcción de textos interdisciplinarios a nivel latinoamericano, ya que de esta manera se podrá condensar un marco epistemológico, teórico y metodológico "localista", es decir, conformar un pensamiento regional crítico que pueda ser identificado por las diferentes geografías, tanto anglosajona, europea y norteamericana.

\section{Referencias bibliográficas}

HARVEY, D. París, capital de la modernidad. Madrid: Ed. Akal, 2008. 